\title{
Statins: we need an independent review
}

\author{
Fiona Godlee editor in chief
}

The BMJ

Statins are back in the news. A review published in the Lancet last week, covered in our news story (doi:10.1136/bmj.i4893), presents what its authors clearly consider to be a definitive account of the evidence on statins that should, they say, bring an end to a dangerous debate.

Not everyone agrees. Though the benefits of statins for secondary prevention or in people at high risk of cardiovascular disease are undisputed, proposals to offer them to large numbers of people at lower risk remain controversial, much to the frustration of the statin trialists who authored the Lancet review. Commenting in The BMJ this week, Harlan Krumholz agrees on the strong case for the overall benefits of statins, but he wants more acknowledgment of the trials' limitations (doi:10.1136/ bmj.i4963). These include the lack of good evidence in elderly people, the variation in how adverse event data were collected, and the ageing of the trials themselves.

In a $B M J$ blog Richard Lehman says that adverse effects are much more common than the trials suggest (blogs.bmj.com/ bmj). "Muscle pain and fatigability are not a figment of misattribution and public misinformation," he says. "They are too prevalent and recurrent in people who desperately want to stay on statins. Rather than discount a widely observed phenomenon, we should ask why there is such a mismatch with reporting in the trials." Could this mismatch be due to exclusion of people who experienced side effects during "run-in periods" before randomisation?

At a more fundamental level, who should decide when such questions are too dangerous to ask? Certainly not those who have a vested interest in the debate being shut down. Rory
Collins, head of the Cholesterol Treatment Trialists' (CTT) Collaboration, continues to call for the retraction of two BMJ articles that disputed the use of statins in low risk people (doi: 10 . 1136/bmj.f6123; doi:10.1136/bmj.f6340). His call comes despite an independent expert panel set up by The BMJ and, subsequently, the Committee on Publication Ethics (COPE) concluding that The BMJ had acted appropriately in its handling of the papers. This week we publish documents (http://www. bmj.com/content/bmj/suppl/2016/11/09/bmj.i4992.DC1/ copedocuments.pdf) that serve to correct Richard Horton's comments in the Lancet (doi:10.1016/S0140-6736(16)315835), in which he wrongly stated that COPE had "declined to act" on Collins's concerns. (See also my rapid response www.bmj. com/content/351/bmj.h3908/rr-8.)

Independent third party scrutiny of the statins trial data remains an essential next step if this increasingly bitter and unproductive dispute is to be resolved. I have now written to England's chief medical officer, Sally Davies, asking her to call for and fund an independent review of the evidence on statins. As Krumholz concludes, sharing the individual patient level data from the statins trials would send "a strong message that no single person or group should have exclusive access to data" that are so important for public health.

For more of The $B M J$ s content relating to the statins debate go to $\mathrm{bmj}$. com/campaign/statins-open-data.

Published by the BMJ Publishing Group Limited. For permission to use (where not already granted under a licence) please go to http://group.bmj.com/group/rights-licensing/ permissions 